\title{
Epigenotype and phenotype correlations in patients with Beckwith-Wiedemann syndrome
}

\author{
Burçak Bilgin ${ }^{1}$, Serkan Kabaçam² ${ }^{2}$, Ekim Taşkıran³ ${ }^{3}$, Pelin Özlem Şimşek-Kiper ${ }^{1}$, Yasemin \\ Alanay $^{1}$, Koray Boduroğlu${ }^{1}$, Gülen Eda Utine ${ }^{1}$ \\ ${ }^{1}$ Division of Pediatric Genetics, ${ }^{2}$ Molecular Genetics Laboratory, Department of Pediatrics; ${ }^{3}$ Department of Medical Genetics, \\ Hacettepe University Faculty of Medicine, Ankara, Turkey. E-mail: drburcakbilgin@gmail.com \\ Received: 5th June 2017, Revised: 9th January 2018, Accepted: 3rd February 2018
}

\begin{abstract}
SUMMARY: Bilgin B, Kabaçam S, Taşkıran E, Şimşek-Kiper PÖ, Alanay Y, Boduroğlu K, Utine GE. Epigenotype and phenotype correlations in patients with Beckwith-Wiedemann syndrome. Turk J Pediatr 2018; 60: 506-513.

Beckwith-Wiedemann Syndrome (BWS) is one of the most common overgrowth syndromes. Cancer predisposition is an important feature of this clinically heterogeneous syndrome. Patients may have fetal and early childhood overgrowth, hemihyperplasia, macroglossia, facial dysmorphic features, abdominal wall defects, visceromegaly, and anomalies of the heart and the kidneys. Various previous investigations showed that heterogeneous molecular etiology may contribute to clinical variability and that epigenotype-phenotype correlations exist in BWS. This study was performed to detect the molecular etiology in 28 patients with BWS, to search for epigenotype-phenotype correlations and to provide appropriate individualized multidisciplinary approach. Four different molecular etiology groups were determined based on testing for copy number analysis and methylation status at $11 \mathrm{p} 15$. Sequencing for CDKN1C mutations were also performed. Groups were compared for various clinical findings. Differences between groups were not statistically significant owing to the small number of patients in individual groups. Statistical studies for epigenotype-phenotype correlations showed significance for only anterior ear lobe creases, visceromegaly and embryonal tumors. Additionally, one interesting patient had a mesenchymal tumor. Anticipating follow-up is clinically important in BWS.
\end{abstract}

Key words: Beckwith-Wiedemann syndrome (BWS), epigenotype and phenotype correlation, imprinting, uniparental disomy, Wilms tumor.

Beckwith-Wiedemann syndrome (BWS) (OMIM \#130650) is one of the best known and most common overgrowth syndromes. Incidence of BWS is about one in 13,700 live births. ${ }^{1,2}$ The clinical presentation is very heterogeneous and patients with mild phenotypical features may remain undiagnosed, suggesting a higher actual incidence for the disease. ${ }^{3-5}$

The disease is sporadic in most patients $(85 \%)$ and familial in a few (15\%). ${ }^{4-6}$ Underlying molecular pathology in BWS is heterogeneous, and may be responsible from the variability of clinical features. 7,8 BWS is clinically characterized by macrosomia, macroglossia, abdominal wall defects, visceromegaly, hemihyperplasia, embryonal tumors, neonatal hypoglycemia, ear anomalies, adrenocortical cytomegaly, and renal anomalies. ${ }^{9}$ In addition to systemic problems related to overgrowth, various anomalies involving face, abdominal wall, heart and kidneys, most important clinical problem is predisposition to malignancies. ${ }^{10}$ Predisposition to Wilms tumor as well as to other embryonal tumors like hepatoblastoma, rhabdomyosarcoma, neuroblastoma, and adrenocortical carcinoma can be observed.5,11,12 Tumor development may be seen in approximately $7.5 \%$ of the patients. ${ }^{11,13-15}$ Therefore appropriately 
diagnosing the syndrome, through careful evaluation of all potential clinical features and molecular testing, has great clinical importance.

Molecular pathology in BWS may be caused by a variety of genetic and epigenetic alterations, affecting expression of imprinted growth regulating genes localized on chromosome 11p15.5.4 These changes are collectively responsible from $80 \%$ of cases. ${ }^{16}$ Two imprinted gene clusters found on chromosome 11p15.5, IGF2/H19 domain and CDKN1C/KCNQ1OT1/ KCNQ1 domain, are functionally regulated by two imprinting centers, IC 1 and IC 2 , respectively. Loss of normal function of these imprinted domains may lead to BWS. The mechanisms include loss of maternal methylation at IC2 in $50-60 \%$ of patients, paternal uniparental disomy (UPD) (causing biallelic paternal expression profile in both domains) in 20\%, maternal CDKN1C mutations in $5-10 \%$, and maternal hypermethylation of IC 1 in $2-7 \%$ of patients. In less than $1 \%$ of patients, paternal $11 \mathrm{p} 15$ duplication causes dominance of a paternal expression profile at this region. Maternal cytogenetic anomalies like translocations or inversions may cause loss of maternal expression pattern in less than $1 \%$. In the remaining $13-15 \%$, underlying molecular etiology cannot be determined.

It is presumed that the clinical spectrum of variable features in BWS may be related to the heterogeneity of the underlying molecular mechanisms, as presented in Table I. ${ }^{9}$ This current study has been conducted in search for 1) the underlying molecular etiology in a group of BWS patients using methylation sensitive multiplex ligation-dependent probe amplification (MS-MLPA) and CDKN1C sequencing, and 2) potential epigenotypephenotype correlations.

\section{Material and Methods}

This study was performed between July 2011 and August 2012 at Hacettepe University, İhsan Doğramacı Children's Hospital, Division of Pediatric Genetics. Twenty-eight patients clinically consistent with BWS were included in the study. There are no absolute requisites for the clinical diagnosis of BWS. It is generally accepted that the presence of at least three major findings, or two major findings and one minor finding support a clinical diagnosis (Table II). ${ }^{15}$ Thus, the clinical diagnoses were based on the presence of these clinical criteria.

MS-MLPA reaction, using the commercially available kit SALSA MS-MLPA probemix ME030-C1 BWS/RSS was performed as recommended by the manufacturer (MRCHolland ${ }^{\circledR}$, Amsterdam, The Netherlands). Cytogenetic analyses were performed on GTG-banded metaphase spreads prepared from phytohemagglutinin (PHA)-stimulated peripheral blood lymphocytes after standard culture and chromosome preparation techniques. Chromosome analyses were performed at a resolution of 550 bands. Molecular analysis for CDKN1C was performed via sequencing. For this, genomic DNA was extracted from peripheral blood lymphocytes using The QIAamp DNA Blood Mini Kit (Qiagen) according to manufacturer's recommendations. Sanger sequencing of CDKN1C gene was performed using BigDye terminator chemistry 3.1 on the 3130 Genetic Analyzer (Applied Biosystems). Primer sequences and PCR conditions are available on request.

According to the underlying molecular etiology, patients were grouped into four as follows; Group 1: loss of methylation at IC2; Group 2: gain of methylation at IC1; Group 3: paternal UPD, and Group 4: other molecular mechanisms. Patients were then examined in terms of clinical characteristics, including presence or absence of polyhydramnios, large placenta, prematurity, birth via assisted reproductive techniques (ART), high birth weight, neonatal hypoglycemia, macrosomia, anterior abdominal wall defects, macroglossia, typical facial characteristics including flat face, hypertelorism, micrognathia, facial nevus flammeus/ hemangioma, anterior ear lobe crease, posterior helical pits, hemihyperplasia, nephromegaly, visceromegaly, embryonal tumors, as well as for presence of hypocalcemia, hypoglycemia, hypercholesterolemia, hypothyroidism, hypercalciuria and nephrocalcinosis.

Statistical analyses were performed using Statistical Package for the Social Sciences (SPSS) version 18.0. Descriptive statistics included count and percentage in qualitative variables; and mean, standard deviation, median, minimum and maximum values for numeric variables. Relationships between qualitative variables were studied using $\chi^{2}$ and Fisher's exact $\chi 2$ tests. Mann-Whitney $U$ and 
Table I. Epigenotype-Phenotype Correlations in Beckwith-Wiedemann Syndrome. ${ }^{9}$

\begin{tabular}{|c|c|}
\hline Clinical features & Molecular etiology \\
\hline Hemihyperplasia & $\begin{array}{l}\text { UPD (most frequent) } \\
\text { Gain of methylation at IC1 (less frequent) } \\
\text { Loss of methylation at IC2 (less frequent) }\end{array}$ \\
\hline Positive family history & $\begin{array}{l}\text { CDKN1C mutation } \\
\text { Microdeletion at IC1 } \\
\text { Microduplication at IC2 (rare) } \\
\text { 11p15 translocations/inversions } \\
\text { 11p15 duplication }\end{array}$ \\
\hline Cleft palate & CDKN1C mutation \\
\hline Omphalocele & CDKN1C mutation \\
\hline Tumor type (tumor risk) & Loss of methylation at IC2 \\
\hline Wilms tumor $(>25 \%)$ & $\begin{array}{l}\text { UPD } \\
\text { Gain of methylation at IC1 }\end{array}$ \\
\hline Hepatoblastoma $(>25 \%)$ & $\begin{array}{l}\text { UPD } \\
\text { Gain of methylation at IC1 }\end{array}$ \\
\hline Embryonal tumors other than Wilms tumor (5\%) & Loss of methylation at IC2 \\
\hline Neuroblastoma only $(<5 \%)$ & CDKN1C mutation \\
\hline Developmental delay & 11p15 duplication (cytogenetically visible) \\
\hline Severe BWS phenotype & High levels of UPD \\
\hline \multicolumn{2}{|l|}{ Monozygotic twinning } \\
\hline Female and discordant & Loss of methylation at IC2 \\
\hline Male and discordant or concordant & $\begin{array}{l}\text { UPD } \\
\text { Gain of methylation at IC1 } \\
\text { Loss of methylation at IC2 }\end{array}$ \\
\hline BWS following subfertility with or without ART & Loss of methylation at IC2 \\
\hline
\end{tabular}

ART: assisted reproductive techniques, BWS: Beckwith-Wiedemann syndrome, CDKN1C: cyclin-dependent kinase inhibitor 1C, IC: imprinting center, UPD: uniparental disomy

Kruskal-Wallis tests were used in comparison of numerical values between groups. In all statistical tests, a $\mathrm{p}$ value of less than 0.05 has been considered as statistically significant.

This study was approved by the Hacettepe University Ethics Committee, and was financially supported by the Hacettepe University Scientific Research and Development Office. Verbal and written informed consents were obtained from parents of all patients.

\section{Results}

All of the patients met the clinical diagnostic criteria in Table II. Clinical features of the patients are summarized in Table III-IV.

Molecular etiology of BWS has been determined in 19 of 28 patients; 13 patients were included in Group $1(13 / 28 ; 46 \%)$, two patients in Group $2(2 / 28 ; 7 \%)$, four patients in Group 3
$(4 / 28 ; 14 \%)$ and remaining nine patients were grouped into Group $4(9 / 28 ; 32 \%)$. None of the patients had cytogenetic alterations, paternal duplications or CDKN1C mutations. None of the patients had positive family history.

Clinical and radiological findings of the patient groups are summarized in Tables III-V. Groups were statistically similar in terms of sex, age and body measurements (Table III). Statistical studies for epigenotype-phenotype correlations showed significance for only anterior ear lobe creases, visceromegaly and embryonal tumors (Table IV). Embryonal tumors consisted of one Wilms tumor in each group, and a second patient in Group 2 who had malignant mesenchymal tumor with epitheloid sarcomatous and rhabdoid components. Ages at diagnosis were 11, 19, 36 and 54 months for Wilms tumor in four 
groups, respectively, and was 20 months for malignant mesenchymal tumor.

Findings in abdominal and renal ultrasonography are presented in Table V. The two patients in Group 2 had positive findings in ultrasonography $(100 \%)$ and this difference was statistically significant $(\mathrm{p}=0.030)$. No statistically significant differences were observed regarding other parameters, as shown in Tables III-V (all $\mathrm{p}>0.05)$.

\section{Discussion}

BWS is a molecularly and clinically heterogeneous disorder. BWS patients benefit from a definite molecular diagnosis, allowing physicians to determine individual risks more accurately and follow patients properly. This current study showed some epigenotype-phenotype correlations exist in a cohort of 28 patients with BWS. The statistical yield would be much higher in a larger cohort, nevertheless, the results add to the existing data from previous studies.

Statistically significant differences in subgroups were observed for three clinical features only; anterior ear lobe creases, visceromegaly and embryonal tumors. Of these, anterior ear lobe creases and posterior helical pits were previously reported in $63 \%$ of patients. 5,17 In our cohort $9 / 28(32.1 \%)$ of patients had anterior ear lobe creases. Statistically significant difference between groups $(\mathrm{p}=0.028)$ emerged since $8 / 13$ patients $(61.5 \%)$ in Group 1 had creases. This correlation had not been reported in the literature previously and should be confirmed in studies with larger groups.

Visceromegaly involving liver, spleen, pancreas, kidneys and adrenals can be found in patients with BWS. We have seen that visceromegaly affected $12 / 28(42.9 \%)$ of patients, the difference between the groups being statistically significant $(\mathrm{p}=0.016)$. This difference was in between Group 1 (11/13 without visceromegaly) and Group 2 (both 2 with visceromegaly), although this comparison was statistically poor due to very low number of patients.

A statistically significant difference was also detected for embryonal tumor development $(p=0.039)$. Absence of tumors in Group 1 in $12 / 13$ and presence of tumors in $2 / 2$ in group 2 has probably been the reason of this statistical difference. In patients with BWS, tumor development risk varies from $4 \%$ to $21 \%$, with an average of 7.5\%.5,9,11,17-19 Tumors are mostly detected in the first decade but may

Table II. Major and Minor Findings Associated with Beckwith-Wiedemann syndrome. ${ }^{15}$

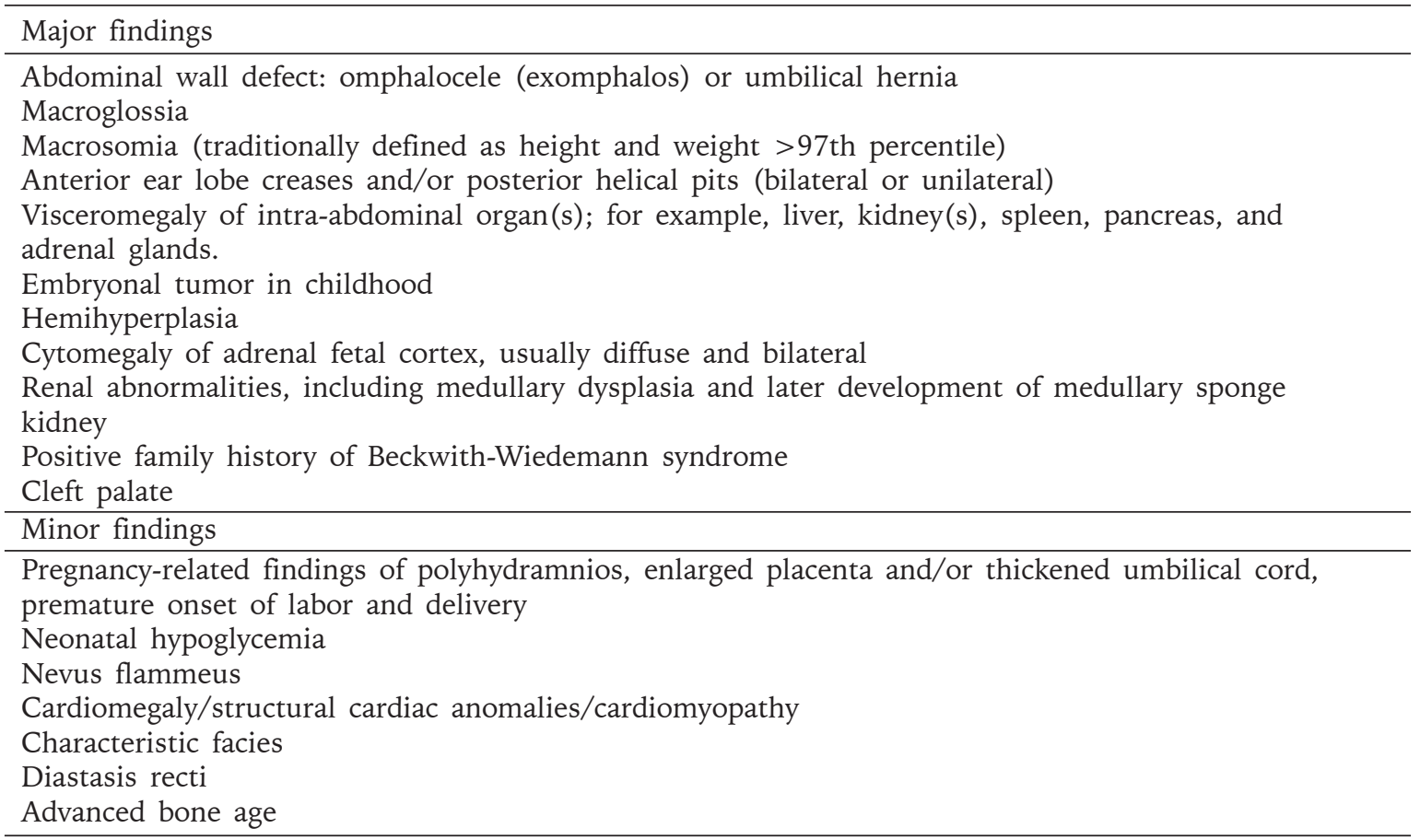


Table III. Gender, Age, Body Measurements of Patients.

\begin{tabular}{lcccccc}
\hline & $\begin{array}{c}\text { Group 1 } \\
(\mathrm{n}=13)\end{array}$ & $\begin{array}{c}\text { Group 2 } \\
(\mathrm{n}=2)\end{array}$ & $\begin{array}{c}\text { Group 3 } \\
(\mathrm{n}=4)\end{array}$ & $\begin{array}{c}\text { Group 4 } \\
(\mathrm{n}=9)\end{array}$ & $\begin{array}{c}\text { Total } \\
(\mathrm{n}=28)\end{array}$ & $\mathrm{p}$ \\
\hline Female/male, $\mathrm{n} / \mathrm{n}$ & $4 / 9$ & $1 / 1$ & $1 / 3$ & $4 / 5$ & $10 / 18$ & 0.934 \\
Age, month* & $47.5 \pm 34.6$ & $48.0 \pm 24.6$ & $82.1 \pm 23.6$ & $45.2 \pm 34.9$ & $51.7 \pm 33.7$ & 0.209 \\
Body weight, kg* & $20.4 \pm 12.8$ & $22.7 \pm 16.6$ & $25.6 \pm 11.0$ & $17.6 \pm 10.2$ & $20.4 \pm 11.6$ & 0.480 \\
Height, cm* & $101.1 \pm 24.2$ & $100.5 \pm 26.1$ & $113.8 \pm 10.5$ & $95.2 \pm 22.5$ & $101.0 \pm 22.0$ & 0.579 \\
Head circumference, cm* & $50.0 \pm 3.1$ & $50.0 \pm 4.2$ & $51.8 \pm 1.5$ & $48.9 \pm 3.9$ & $49.9 \pm 3.2$ & 0.494 \\
\hline
\end{tabular}

*Data is presented as mean \pm standard deviation

also develop in older ages. ${ }^{11,20}$ The mean age of 28 patients in our study was $51.7 \pm 33.7$ months, youngest patient being 9-months old and the oldest one being 120-months old. This result supports that the most important period is the first 8-10 years of life for development of embryonal malignant diseases. The rate of tumor development in our study $(17.9 \%)$ was consistent with previous literature, however, as $24 / 28$ patients were younger than 8 years of age, one can assume that overall rate could be higher after a certain period of follow-up.
Wilms tumor was found in one patient per group and malignant mesenchymal tumor, with some characteristics of both epithelioid sarcoma and rhabdoid elements, was found in the second patient in Group 2. This interesting patient in Group 2 had malignant mesenchymal tumor that developed at 20 months of age. She was diagnosed with BWS at birth on detection of macroglossia, visceromegaly, polyhydramnios, prematurity, birth weight over 97th centile, neonatal hypoglycemia and facial characteristics including micrognathia, hypertelorism and flat face. Malignant mesenchymal tumor, which

Table IV. The Clinical Findings of Patients.

\begin{tabular}{lcccccc}
\hline Findings & $\begin{array}{c}\text { Group } 1 \\
(\mathrm{n}=13)\end{array}$ & $\begin{array}{c}\text { Group 2 } \\
(\mathrm{n}=2)\end{array}$ & $\begin{array}{c}\text { Group } 3 \\
(\mathrm{n}=4)\end{array}$ & $\begin{array}{c}\text { Group } 4 \\
(\mathrm{n}=9)\end{array}$ & $\begin{array}{c}\text { Total }(\mathrm{n}=9) \\
\mathrm{n}(\%)\end{array}$ & $\mathrm{p}$ \\
\hline Macrosomia & $4(30.8)$ & $1(50.0)$ & $1(25.0)$ & $3(33.3)$ & $9(32.1)$ & 1.000 \\
ART & $2(15.4)$ & - & - & - & $2(7.1)$ & 0.690 \\
Anterior abdominal wall defect & $8(61.5)$ & - & $1(25.0)$ & $3(33.3)$ & $12(42.8)$ & 0.862 \\
Macroglossia & $12(92.3)$ & $1(50.0)$ & $3(75.0)$ & $5(55.5)$ & $21(75.0)$ & 0.176 \\
Hemihyperplasia & $8(61.5)$ & $1(50.0)$ & $4(100.0)$ & $8(88.8)$ & $21(75.0)$ & 0.225 \\
Hemihyperplasia right side & $5(38.5)$ & - & $3(75.0)$ & $7(77.7)$ & $15(53.5)$ & 0.232 \\
Hemihyperplasia left side & $3(23.1)$ & $1(50.0)$ & $1(25.0)$ & $1(11.1)$ & $6(21.4)$ & 0.232 \\
Anterior ear lobe crease & $8(61.5)$ & - & - & $1(11.1)$ & $9(32.1)$ & 0.028 \\
Posterior helical pit & $8(61.5)$ & $1(50.0)$ & $1(25.0)$ & $1(11.1)$ & $11(39.2)$ & 0.078 \\
Visceromegaly & $2(15.4)$ & $2(100.0)$ & $2(50.0)$ & $6(66.6)$ & $12(42.8)$ & 0.016 \\
Embryonal tumor & $1(7.7)$ & $2(100.0)$ & $1(25.0)$ & $1(11.1)$ & $5(17.8)$ & 0.039 \\
Polyhydramnios & $5(38.5)$ & $1(50.0)$ & $1(25.0)$ & $1(11.1)$ & $8(28.5)$ & 0.479 \\
Large placenta & $1(7.7)$ & - & - & - & $1(3.5)$ & 1.000 \\
Prematurity & $5(38.5)$ & $1(50.0)$ & $2(50.0)$ & $2(22.2)$ & $10(35.7)$ & 0.681 \\
High birth weight & $6(46.2)$ & $2(100.0)$ & $2(50.0)$ & $5(55.5)$ & $15(53.5)$ & 0.740 \\
Neonatal hypoglycemia & $6(46.2)$ & $1(50.0)$ & $1(25.0)$ & $2(22.2)$ & $10(35.7)$ & 0.598 \\
Facial nevus flammeus & $9(69.2)$ & - & $1(25.0)$ & $3(33.3)$ & $13(46.4)$ & 0.161 \\
hemangioma & & & & & & \\
Facial characteristics & $11(84.6)$ & $2(100.0)$ & $2(50.0)$ & $8(88.8)$ & $23(82.1)$ & 0.333 \\
\hline ART asstan & & & & & & \\
\hline
\end{tabular}

ART: assisted reproductive techniques

Data is presented as $n(\%)$ 
takes origin from mesenchymal tissue and covers $4-8 \%$ of all childhood cancers, has not been reported previously in BWS ${ }^{14}$. Wilms tumor mostly accompanies UPD and gain of methylation at $\mathrm{IC} 1^{6,13}$, but still, our finding should be interpreted with caution because of small groups.

Imprinting disorders like BWS are seen more frequently in children born by ART, and in those with BWS, loss of methylation at IC2 in maternal allele is responsible. ${ }^{21-24}$ It is still not clear whether this situation is due to the process itself or to infertility or to a combination of genetic and environmental predispositions. ${ }^{24}$ Consistently in our study, $2 / 28(7 \%)$ had a history of ART and both had maternal loss of methylation at IC2 (2/13; $15.4 \%)$.

Anterior abdominal wall defects including omphalocele, umbilical hernia, diastasis recti are among the major features of BWS, seen in $77-91 \%$ of patients. ${ }^{1,5,19}$ In patients with omphalocele, CDKN1C mutations were more likely the cause of BWS, whereas loss of maternal methylation at IC2 were less likely. ${ }^{9}$ In our cohort, omphalocele was found in groups 1 and 4, but not in other groups, in accordance with previous studies. ${ }^{25}$ For umbilical hernia, an epigenotype-phenotype correlation has not been established previously. In Group 2, neither of the two patients had umbilical hernia or omphalocele, while a statistically significant conclusion is difficult to draw from this.

Hemihyperplasia is reported in $25 \%$ of patients with BWS. ${ }^{10}$ In previous studies, hemihyperplasia was most commonly related to UPD, and less frequently related to IC1 and IC2 defects. ${ }^{25,26}$ In our cohort, hemihyperplasia was present in $75 \%$ of patients $(21 / 28)$. Renal anomalies involving medulla and collecting ducts are seen in $15-25 \%$ of BWS patients. ${ }^{27}$ Various abdominorenal ultrasonographic anomalies were detected in $50 \%(14 / 28)$ of our patients (Table V). Differences between groups were statistically significant $(\mathrm{p}=0.030)$, which may be partly due to $3 / 13$ (48\%) affected in Group 1 versus 2/2 (100\%) in Group 2.

Another feature of BWS is that the tissues may be affected in a mosaic form. Patients with clinically mild phenotypic features (e.g., macroglossia or umbilical hernia) may develop tumors associated with BWS in molecularly affected tissues only such as kidney and liver. 28 Considering this and the low number of patients in some of our groups, we conclude that screening for embryonal tumors must be prudently done in patients with one or more clinical features suggesting BWS. Abdominal ultrasound every 3 months up to 8 years of age and measurement of AFP level every 3 months up to 4 years of age is recommended for cancer screening in BWS patients. ${ }^{11,29}$

Table V. Abnormalities on Abdominorenal Ultrasounds of Patients.

\begin{tabular}{llllll}
\hline Findings & $\begin{array}{l}\text { Group } 1 \\
(\mathrm{n}=13)\end{array}$ & $\begin{array}{c}\text { Group 2 } \\
(\mathrm{n}=2)\end{array}$ & $\begin{array}{c}\text { Group 3 } \\
(\mathrm{n}=4)\end{array}$ & $\begin{array}{l}\text { Group 4 } \\
(\mathrm{n}=9)\end{array}$ & $\begin{array}{l}\text { Total } \\
(\mathrm{n}=28)\end{array}$ \\
\hline Hepatomegaly & $2(15.4)$ & $1(50.0)$ & $2(50.0)$ & $4(44.4)$ & $9(32.1)$ \\
Nephromegaly & $1(7.7)$ & $2(100.0)$ & $2(50.0)$ & $3(33.3)$ & $8(28.5)$ \\
Adrenocortical thickening & - & - & $2(50.0)$ & - & $2(7.1)$ \\
Splenomegaly & - & - & $1(25.0)$ & $1(11.1)$ & $2(7.1)$ \\
$\begin{array}{l}\text { Collecting system } \\
\text { dilatation }\end{array}$ & - & - & $1(25.0)$ & - & $1(3.5)$ \\
Hydronephrosis & - & - & - & $1(11.1)$ & $1(3.5)$ \\
Nephrocalcinosis & - & - & $1(25.0)$ & $1(11.1)$ & $2(7.1)$ \\
Renal medullary dysplasia & - & - & $1(25.0)$ & - & $1(3.5)$ \\
Wilms tumor & $1(7.7)$ & $1(50.0)$ & $1(25.0)$ & $1(11.1)$ & $4(14.2)$ \\
Liver cyst & - & - & - & $1(11.1)$ & $1(3.5)$ \\
Accessory spleen & - & - & - & $1(11.1)$ & $1(3.5)$ \\
Normal & $10(76.9)^{*}$ & - & $1(25.0)$ & $1(11.1)$ & $12(42.8)$ \\
\end{tabular}

Data is presented as $\mathrm{n}(\%)$

*: Ultrasound abnormalities in Group 1 were significantly less common, compared to other Groups $(p=0.030)$ 
Molecular studies should also be performed for patients with isolated hemihyperplasia. In the literature, $5.9 \%$ increase in the risk of tumor development has been reported in patients with isolated hemihyperplasia. ${ }^{30}$ Choyke et al. ${ }^{31}$ has reported that when patients with BWS or isolated hemihyperplasia are not screened by abdominal US for tumor every 4 months or more frequently, at the time of diagnosis high grade (grade 3 or 4 ) Wilms tumor rates are greater than screened population. Minimal clinical features of BWS, such as isolated hemihyperplasia, should be carefully managed and molecular genetic tests should be recommended. ${ }^{28}$

This study aimed to investigate the relationship between phenotypic expression of BWS and specific molecular subgroups. Although relative percentages of the molecular subgroups were consistent with the previously reported studies, small number of the study population was a limitation of this study. Studies covering larger groups of patients may render the assessment of priority of major and minor clinical features in BWS and clinical diagnosis of the syndrome may be revised.

In conclusion, investigating the underlying molecular etiology in BWS should be recommended even in patients with few clinical characteristics, since molecular changes may be detected even in patients with isolated hemihyperplasia. Embryonal malignancies, particularly Wilms tumor should be screened in all patients with BWS, as these are seen more commonly than in general population. Rare embryonal tumors like malignant mesenchymal tumor may as well be encountered in patients with BWS. A multidisciplinary approach is essential in follow-up of patients with BWS, and intra-abdominal pathology other than tumors should also be investigated.

\section{REFERENCES}

1. Thorburn MJ, Wright ES, Miller CG, Smith-Read EH. Exomphalos-macroglossia-gigantism syndrome in Jamaican infants. Am J Dis Child 1970; 119: 316-321.

2. Engström W, Lindham S, Schofield P. WiedemannBeckwith syndrome. Eur J Pediatr 1988; 147: 450-457.

3. Greer KJ, Kirkpatrick SJ, Weksberg R, Pauli RM. Beckwith-Wiedemann syndrome in adults: Observations from one family and recommendations for care. Am J Med Genet Part A 2008; 146A: 1707-1712.
4. Weksberg R, Shuman C, Smith AC. BeckwithWiedemann syndrome. Am J Med Genet Part C Semin Med Genet 2005; 137C: 12-23.

5. Cohen MM, Jr. Beckwith-Wiedemann syndrome: Historical, clinicopathological, and etiopathogenetic perspectives. Pediatr Dev Pathol 2005; 8: 287-304.

6. Rump P, Zeegers MP, van Essen AJ. Tumor risk in Beckwith-Wiedemann syndrome: A review and metaanalysis. Am J Med Genet Part A 2005; 136: 95-104.

7. Cohen MM, Jr. Overgrowth syndromes: An update. Adv Pediatr 1999; 46: 441-491.

8. Maher ER, Reik W. Beckwith-Wiedemann syndrome: Imprinting in clusters revisited. J Clin Invest 2000; 105: 247-252.

9. Choufani S, Shuman C, Weksberg R. BeckwithWiedemann syndrome. Am J Med Genet C Semin Med Genet 2010; 154C: 343-354.

10. Elliott M, Maher ER. Beckwith-Wiedemann syndrome. J Med Genet 1994; 31: 560-564.

11. Tan TY, Amor DJ. Tumour surveillance in BeckwithWiedemann syndrome and hemihyperplasia: A critical review of the evidence and suggested guidelines for local practice. J Paediatr Child Health 2006; 42: 486490.

12. Wiedemann HR. Tumours and hemihypertrophy associated with Wiedemann-Beckwith syndrome. Eur J Pediatr 1983; 141: 129

13. Bliek J, Maas SM, Ruijter JM, et al. Increased tumour risk for BWS patients correlates with aberrant H19 and not KCNQ1OT1 methylation: Occurrence of KCNQ1OT1 hypomethylation in familial cases of BWS. Hum Mol Genet 2001; 10: 467-476.

14. Cooper WN, Luharia A, Evans GA, et al. Molecular subtypes and phenotypic expression of BeckwithWiedemann syndrome. Eur J Hum Genet 2005; 13: 1025-1032.

15. Weksberg R, Shuman C, Beckwith JB. BeckwithWiedemann syndrome. Eur J Hum Genet 2010; 18: 8-14.

16. Weksberg R, Smith AC, Squire J, Sadowski P. Beckwith-Wiedemann syndrome demonstrates a role for epigenetic control of normal development. Hum Mol Genet 2003; 12: R61-R68.

17. Elliott M, Bayly R, Cole T, Temple IK, Maher ER. Clinical features and natural history of BeckwithWiedemann syndrome: Presentation of 74 new cases. Clin Genet 1994; 46: 168-174.

18. Weng EY, Moeschler JB, Graham JM Jr. Longitudinal observations on 15 children with Wiedemann-Beckwith syndrome. Am J Med Genet 1995; 56: 366-373.

19. Pettenati MJ, Haines JL, Higgins RR, Wappner RS, Palmer CG, Weaver DD. Wiedemann-Beckwith syndrome: Presentation of clinical and cytogenetic data on 22 new cases and review of the literature. Hum Genet 1986; 74: 143-154.

20. DeBaun MR, Siegel MJ, Choyke PL. Nephromegaly in infancy and early childhood: A risk factor for Wilms tumor in Beckwith-Wiedemann syndrome. J Pediatr 1998; 132: 401-404. 
21. DeBaun MR, Niemitz EL, Feinberg AP. Association of in vitro fertilization with Beckwith-Wiedemann syndrome and epigenetic alterations of LIT1 and H19. Am J Hum Genet 2003; 72: 156-160.

22. Gicquel C, Gaston V, Mandelbaum J, Siffroi JP, Flahault A, Le Bouc Y. In vitro fertilization may increase the risk of Beckwith-Wiedemann syndrome related to the abnormal imprinting of the KCN1OT gene. Am J Hum Genet 2003; 72: 1338-1341.

23. Halliday J, Oke K, Breheny S, Algar E, J Amor D. Beckwith-Wiedemann syndrome and IVF: A case-control study. Am J Hum Genet 2004; 75: 526-528.

24. Maher ER, Afnan M, Barratt CL. Epigenetic risks related to assisted reproductive technologies: Epigenetics, imprinting, ART and icebergs? Hum Reprod 2003; 18: 2508-2511.

25. Enklaar T, Zabel BU, Prawitt D. Beckwith-Wiedemann syndrome: Multiple molecular mechanisms. Expert Rev Mol Med 2006; 8: 1-19.

26. DeBaun MR, Niemitz EL, McNeil DE, Brandenburg SA, Lee MP, Feinberg AP. Epigenetic alterations of H19 and LIT1 distinguish patients with Beckwith-Wiedemann syndrome with cancer and birth defects. Am J Hum Genet 2002; 70: 604-611.
27. Goldman M, Smith A, Shuman C, et al. Renal abnormalities in Beckwith-Wiedemann syndrome are associated with 11p15.5 uniparental disomy. J Am Soc Nephrol 2002; 13: 2077-2084.

28. Reish O, Lerer I, Amiel A, et al. Wiedemann-Beckwith syndrome: Further prenatal characterization of the condition. Am J Med Genet 2002; 107: 209-213.

29. Zarate YA, Mena R, Martin LJ, Steele P, Tinkle BT Hopkin RJ. Experience with hemihyperplasia and Beckwith-Wiedemann syndrome surveillance protocol. Am J Med Genet Part A 2009; 149A: 1691-1697.

30. Hoyme HE, Seaver LH, Jones KL, Procopio F, Crooks W, Feingold M. Isolated hemihyperplasia (hemihypertrophy): Report of a prospective multicenter study of the incidence of neoplasia and review. Am J Med Genet 1998; 79: 274-278.

31. Choyke PL, Siegel MJ, Craft AW, Green DM, DeBaun MR. Screening for Wilms tumor in children with Beckwith-Wiedemann syndrome or idiopathic hemihypertrophy. Med Pediatr Oncol 1999; 32: 196200. 